\title{
PhD Defence: "Iranian Community Media in Stockholm: Locality, Transnationality, and Multicultural Adaptation" by Daniel Ahadi
}

\author{
Vu Thuy Anh Phan \\ School of Communication \\ Simon Fraser University
}

Our dear colleague, Daniel Ahadi, will defend his PhD Dissertation on Monday, June 27, 2016 at Harbour Centre, Library Thesis Room, Bennett Library Room 2020, (10:30 am 1:30 pm). Here is the abstract of his dissertation "Iranian Community Media in Stockholm":

\begin{abstract}
:
This study of Iranian diasporic media is located in Stockholm which became an important intellectual centre for Iranian exilic political activities in the 1980s. Employing interviews, textual analysis and policy research methods, this dissertation finds that Iranian ethnic media (and particularly radio) in Stockholm have demonstrated resilience and managed to stay relevant despite threats from commercialization and multiplication of competition from new international satellite and internet information providers. Such outlets are stronger than ever, and in a population well into its second and third generations, on the precipice of generational change.
\end{abstract}

Very little about the Iranian media in Stockholm studied suggests they channel a cosmopolitan or intercultural discourse, refuting Hamid Dabashi's simple account of "cosmopolitan dispositionality" of Iranians (2007). Instead, they foster an ethno-centric, nostalgic "Persianist" subjectivity because the language is exclusively Persian, with no minority languages represented; they exhibit intracultural marginalization, while largely excluding women, youth and religious minority voices; show little content or organizational outreach; do not tend to collaborate and rarely translate into Swedish to raise intercultural awareness. Nonetheless, while many have failed and others arisen, they continue to give voice and represent community and locality in ways that no Internet platform and satellite television can because they offer an important sounding board for orientations to identity as "Iranian" or "Persian" within the local socio-cultural context, proving crucial in the process of "onboarding" into the Swedish society.

The main argument is that the field of diasporic and ethnic media studies has to disrupt both celebratory and cosmopolitan tendencies, and victimization and minority discourses. Sweden proves a useful ground to explore the neoliberal turn and its disruptive impacts on universalist and social democratic civic ideals, to disclose the parlous circumstance of community media even amongst an allegedly advanced social welfare state under recent Conservative attack and the institutional failures of assimilative strategies in humanitarian and refugee immigration, and multicultural media infrastructure among diasporic peoples. Only 
through careful, non-media centric study of the multicultural communication infrastructure can researchers begin to grasp the symbolic and connective needs of different diasporic communities.

While the Swedish cultural preference for social democratic universalism has repeatedly rejected affirmative action policies for immigrants on the part of both the left and the right, this is no longer viable. This study concludes with suggestions for the concrete affirmative steps that can be taken to both strengthen the institutional capacity of immigrants in their chosen communities, and their ethnic media and expand its intercultural appeal in Stockholm. It is intended to contribute to other emerging anti- hegemonic studies by Elingson (2009), Kosnick (2007), Aksoy and Robins (2003), and Madianou (2005) which approach the question of situated identity and formation of belonging without getting trapped in the infinite loop of hybridity.

Keywords: Iranian media; diaspora; Sweden; ethnic media; radio; multiculturalism; media policy 